\title{
Glycosaminoglycan-binding microbial proteins in tissue adhesion and invasion: key events in microbial pathogenicity
}

\author{
TORKEL WADSTRÖM and ÅSA LJUNGH
}

Department of Infectious Diseases and Medical Microbiology, Lund University, Sölvegatan 23, S-223 62 Lund, Sweden

\begin{abstract}
Glycosaminoglycans such as heparin, heparan sulphate and dermatan sulphate, are distributed widely in the human body. Several glycosaminoglycans form part of the extracellular matrix and heparan sulphate is expressed on all eukaryotic surfaces. The identification of specific binding to different glycosaminoglycan molecules by bacteria (e.g., Helicobacter pylori, Bordetella pertussis and Chlamydia trachomatis), viruses (e.g., herpes simplex and dengue virus), and protozoa (e.g., Plasmodium and Leishmania), is therefore of great interest. Expression of glycosaminoglycan-binding proteins depends on growth and culture conditions in bacteria, and differs in various phases of parasite development. Glycosaminoglycan-binding microbial proteins may mediate adhesion of microbes to eukaryotic cells, which may be a primary mechanism in mucosal infections, and are also involved in secondary effects such as adhesion to cerebral endothelia in cerebral malaria or to synovial membranes in arthritis caused by Borrelia burgdorferi. It has been suggested that they may enhance intracellular survival in macrophages. Microbial binding of heparin may interfere with heparin-dependent growth factors. Whether or not glycosaminoglycan-binding proteins mediate invasion of epithelial cells is a matter of controversy. Heparin and other glycosaminoglycans may have potential uses as therapeutic agents in microbial infections and could form part of future vaccines against such infections.
\end{abstract}

\section{Introduction}

A number of bacterial, viral and parasitic pathogens have been shown to express surface proteins that interact with specific glycoconjugates on cell surfaces $[1,2]$. Pioneer studies on haemagglutinating Escherichia coli and other enteric organisms, and haemagglutinin and sialidases of influenza virus, were published several decades ago. Development of specific glycoconjugate receptor analogues against influenza virus, as well as receptor analogues to gal-1- $4 \beta$-gal conjugate carbohydrate receptor structures of the blood group antigen for uropathogenic $E$. coli, has encouraged much later research to define specific microbial surface haemagglutinins and other carbohydrate-binding proteins, generally called lectins, as targets for antiadhesion thereapy.

Glycosaminoglycans (GAGs), i.e., heparan sulphate, dermatan sulphate, chondroitin sulphates, keratin

Received 26 June 1998; accepted 14 August 1998.

Corresponding author: Professor T. Wadström. sulphate, heparin and other sulphated molecules, and hyaluronic acid which is unsulphated, are found ubiquitously in the human body. They form a major part of the extracellular matrix (ECM). Heparan sulphate is expressed on the surface of eukaryotic cells and heparin is present in mast cells. Cell surface GAG molecules mediate many cellular processes. Among these are cell-ECM adhesion $[3,4]$, cell migration and growth, and various cellto-cell signalling processes $[1,5]$. They also bind growth factors, growth factor-binding proteins, apolipoprotein, proteases and protease inhibitors [6]. Many pathogenic bacteria, viruses, fungi and parasites have learnt to use cell surface glycolipids, glycoproteins and GAGs as receptor molecules for cell attachment, as well as eukaryotic cell invasion and intercellular migration processes. These interactions usually involve specific surface proteins of micro-organisms, named adhesins. As these proteins commonly interact with specific carbohydrate structures on glycoconjugates, they can also be defined as microbial surface lectins that enable the microbes to initiate an infectious process. 
Microbial binding to glycolipids and glycoproteins by specific surface lectins, often with haemagglutinating (HA) activity, has been discussed extensively elsewhere [7]. In contrast, binding to cell surface and ECM GAGs has been studied poorly, despite the fact that well-defined interactions with heparan sulphate and chondroitin-4-sulphate were described many years ago for herpes simplex virus [8] and, more recently, for bacterial pathogens such as Helicobacter pylori [9], Staphylococcus aureus [10] and Streptococcus pyogenes or group A streptococci [11] (Table 1). Early observations showed that Trypanosoma cruzi possessed a cell-surface protein that bound to specific heparan sulphate molecules on macrophages. This triggers cell uptake and adhesion to specific ECM molecules involved in phagocytic processes, such as fibronectin (Fn) [12]. Another important human parasite, Plasmodium falciparum, was shown to bind two specific ECM molecules, Fn and thrombospondin (TSP), as well as heparin, heparan sulphate and chondroitin sulphate A [13-17]. In 1996 and 1997, two intracellular pathogens, Mycobacterium tuberculosis and Listeria monocytogenes, were shown to bind heparan sulphate by specific surface molecules $[18,19]$, and the first experimental data were presented to prove that binding to this GAG molecule on macrophages and other cells may trigger cellular uptake [19].

This review focuses on GAG molecules as adhesion receptors for bacteria, viruses and parasites. As GAGstructures are terminal carbohydrate structures linked to protein cores buried in cell membranes in the ECM, as well as in intracellular granulae, specific microbial GAG-binding proteins (GAGBPs) may be involved in cell adhesion, cell uptake and invasion, and in various intercellular and ECM tissue penetration processes [1]. Interestingly, two bacterial pathogens, $H$. pylori and Neisseria gonorrhoeae, bind heparin and heparan sulphate $[9,20]$ in the same way as some pathogens commonly defined as extracellular microbes, i.e., Borrelia spp. and Treponema pallidum [21,22]. These pathogens may adapt to multiply in the ECM in various body tissues, without triggering uptake by macrophages and other phagocytes, or by other cells. From current knowledge of the most extensively studied GAG-microbe interactions, an initial cellbinding event must be followed by binding to other cell-surface glycoconjugates, most likely specific cellsurface glycolipids, as in the case of herpes simplex and related viruses such as cytomegalovirus (CMV) and dengue virus [23]. One recent report suggests that prions may also use heparan sulphate or other similar cell surface and ECM molecules, such as laminin, in cellular interactions in the brain and other body tissues. This information should stimulate much research on the interplay of possible multiple glycoconjugate microbial adhesion events in determining the first and later stages of various viral, bacterial and parasitic infections [24].

\section{Glycosaminoglycan and proteoglycan chemistry}

Several cell membrane proteoglycans have single transmembrane-spanning domains in a type I orientation [25], with syndecan-1 as the prototype. The members of this family of so-called core proteins are fibroglycan-syndecan and ryudocan (Table 2). Each of these molecules has conserved attachment sites for 3-5 GAG chains. The syndecans exemplify hybrid proteoglycans as they contain mixtures of the two major types of GAG chains found in animal cells, heparan sulphate and chondroitin-4 sulphate. Other cell-surface proteoglycans include hybrid molecules of $\beta$-glycan and a spliced form of the CD 44 molecule (epiglycan), chondroitin sulphate proteoglycans and thrombomodulin [1]. The other major family of proteoglycans is named glypicans, as the members possess glycosylphosphatidylinositol membrane-spanning domains such as glypican-1 and $\mathrm{K}$ glypican. Unlike the syndicans, the glypicans appear to contain only heparan sulphate chains. Interestingly, expression of these proteoglycans

Table 1. Glycosaminoglycan binding by microbes

\begin{tabular}{lcl}
\hline Organism & Mol. wt $(\mathrm{kDa})$ & GAG-binding molecule \\
\hline Staphylococcus aureus & 60 & Heparin, heparan sulphate \\
Streptococcus pyogenes & $\ldots$ & $\ldots$ \\
Bordetella pertussis (FHA, fimbriae) & $\ldots$ & $\ldots$ \\
Haemophilus influenzae & $\ldots$ & $\ldots$ \\
Chlamydia pneumoniae & $\ldots$ & $\ldots$ \\
Borrelia burgdorferi & $\ldots$ & $\ldots$ \\
Mycobacterium tuberculosis & 28 & Heparin \\
Listeria monocytogenes & $\ldots$ & Heparin, heparan sulphate \\
Neisseria gonorrhoeae (Opa) & $\ldots$ & Heparin \\
Helicobacter pylori & 57 & Heparin, heparan sulphate \\
Yersinia enterocolitica (LcrG) & $\ldots$ & Heparin, dextran sulphate \\
Mycoplasma pneumoniae & $\ldots$ & Dextran sulphate \\
Leishmania donovani & $\ldots$ & $\ldots$ \\
Trypanosoma cruzi (penetrin) & $\ldots$ & $\ldots$ \\
Plasmodium falciparum & $\ldots$ & $\ldots$ \\
Herpes simplex virus (gB, gC) & $\ldots$ & Heparan sulphate \\
Cytomegalovirus & 30,34 & Heparan sulphate \\
Dengue virus & $\ldots$ & $\ldots$ \\
Human immunodeficiency virus & $\ldots$ & $\ldots$ \\
\hline
\end{tabular}


Table 2. Core proteins of glycosaminoglycans

\begin{tabular}{ll}
\hline Core protein & Occurrence \\
\hline Serglycin & $\begin{array}{l}\text { Haematopoietic cells; complex with } \\
\text { basic proteases } \\
\text { Epithelia, endothelia; transmembrane } \\
\text { core protein }\end{array}$ \\
Syndecan-1 & $\begin{array}{l}\text { Fibroblasts } \\
\text { Syndecan-2 (fibroglycan) }\end{array}$ \\
Syndecan-3 & Nervous tissues, mesenchymae \\
Syndecan-4: Amphiglycan & Fibroblasts \\
Glypicans & Vascular endothelia \\
Perlecan & Eukaryotic cells \\
CD44 Epiglycan & Basement membranes, cartilage \\
$\beta$-Glycan & Epidermis \\
Agrin, Testican & Receptor for TGF $\beta$ \\
\hline
\end{tabular}

occurs in a tissue-specific manner, although their expression overlaps in some cell types and in the apical and basolateral membranes of polarised epithelial cell monolayers. It is noteworthy that heparin is cleaved from the serglycin core protein in mast cells. Free heparin chains form complexes with basic proteases and peptidases which are packed in secretory granules. Upon degranulation, these are released and the enzymes dissociate. In contrast, heparan sulphate is secreted intact from cells [5].

Proteoglycans exhibit an enormous structural heterogeneity caused by great variations in glycosylation patterns, variations in glycan chain lengths of GAG chains, and variation in the extent and pattern of sulphation and epimerisation $[1,25]$. Various proteoglycans are purified by methods based on different charge properties. Thus, chondroitin sulphate $\mathrm{C}$ and $\mathrm{A}$, usually with one $\mathrm{SO}_{4}$ residue/disaccharide unit, differ from chondroitin sulphate B (syn. dermatan sulphate), which contains more sulphate and iduronic acid instead of the galacturonic acid found in chondroitin sulphate $\mathrm{A}, \mathrm{C}$ and heparan sulphate. Heparan sulphate chains usually contain $0.8-1.4$ sulphate groups/disaccharide unit, while heparins synthesised in intracellular granulae of mast cells contain $\geqslant 2.4$ sulphate groups/ unit [25]. In both heparin and heparan sulphate, these sulphate residues occur at the amino groups and the C-6 hydroxyl groups of glycosamine residues, at C-2 of iduronic acid and glucuronic acid, and sometimes at the $\mathrm{C}-3 \mathrm{OH}$ position of glycosamine residues. Various modifications occur to a greater extent in heparin than in heparan sulphate (e.g., $>80 \%$ of glycosamine residues are $\mathrm{N}$-sulphated compared to $<60 \%$ of heparan sulphate). The content of iduronic acid and the degree of o-sulphation also vary more in heparin.

Intramolecular variations in the GAG chain, chain length and degree of sulphation define how these molecules interact with specific ECM proteins such as Fn, collagen type I (Cn I), laminin, vitronectin $[5,26]$ and, most likely, other molecules such as nidogen, which interacts specifically with Leishmania parasites [27]. Interestingly, so-called heparin-dependent growth factors, the acidic and basic growth factors and platelet-derived growth factor (PDGF) also bind to distinct pentasaccharide units with specifically positioned 3-o sulphated glucosamine residues, shown also to bind to antithrombin III [5]. Thrombin, on the other hand, binds to heparin through non-specific electrostatic association with disaccharides of the heparin chain. A number of serum proteins, such as apolipoprotein and lipoprotein lipase, contain specific peptide sequences of basic and non-polar amino acids that define specific heparin-binding motifs. A heparan sulphate-binding peptide derived from $P$. falciparum $[28,29]$, a chondroitin sulphate-binding protein [17] and the N-terminal region of an actin-binding protein, ActA, of L. monocytogenes [19] have been shown to interact with similar basic synthetic peptides constructed on specific sequences of human serum heparin-binding proteins.

How should specificity in microbial GAG-binding and specific GAGBPs be defined? The best studied GAGbinding system is probably the binding of heparin to antithrombin [5], and much can be learnt from these studies. Several microbial cell-surface proteins interact with highly negatively charged sialic acid-containing glycoconjugates ( $\mathrm{S}$ fimbriae, K99, CFAI and various CFA II surface lectins). Heparin and some other GAG molecules also have a negatively charged surface in vivo.

Vaheri et al. [30] were probably the first to define a heparin-sensitive microbial cell-binding event in studies on the interaction of herpes simplex virus with a monolayer of HeLa cells in tissue cultures. However, the precise mechanism by which heparin blocks cell adhesion of microbes has been difficult to elucidate because of the lack of commercially available purified heparins and heparin-derived fragments, now in clinical use in drugs such as Fragmin ${ }^{\circledR}$ (KABIPharmacia, Stockholm, Sweden) [31,32]. Such fragments of heparin and other GAG chains, as well as those from various natural sulphated carbohydrate polymers such as fucoidan and some carageenans, often called 'heparinoids', are used as inhibitors to define the specificity of sulphate interactions in the binding of viruses, bacteria and parasites to specific tissue culture cells and ECM derived from cells grown on various biosurfaces. A mixture of laminin, collagen type 4 and GAGs (Matrigel ${ }^{\circledR}$; Collaborative Res., Bedford, MA, USA) has been useful in defining heparin-sensitive and heparin-insensitive interactions with ECM-associated proteins and proteoglycans [3]. Moreover, various specific glycosidases, such as heparinase, heparitinases and chondroitin sulphatases, now available from Glycosystems (Oxford) and a few other companies, were used as 'receptor-destroying enzymes' in an analagous manner to the use of various sialidases (neuraminidases) to destroy sialoglycoconjugate cell receptors for influenza virus, Newcastle disease virus and $T$. cruzi [33]. 
When cells are cultured in a medium with inhibitors of GAG synthesis (e.g., xylose residues linked to a hydrophobic glycon such as $\beta$-D xylosides), unglycosylated proteoglycans appear on the cell surface. Alternatively, cells can be grown in a medium deficient in organic sulphate supplemented with sodium chlorate as an inhibitor of GAG sulphation [1]. However, use of the $\beta$-xyloside or the chlorate method will also cause undersulphation of other sulphated cell-surface glycoconjugates such as various glycolipids or sulphatides. Mutant Chinese hamster ovary cells and mutants of mouse L cells deficient in heparan sulphate and chondroitin sulphate have also been used to define GAG binding of CMV and dengue virus [23].

\section{Binding assays}

Radiolabelled proteoglycans and GAGs can be prepared from cells grown with radioactive GAG precursors such as ${ }^{35} \mathrm{SO}_{4}$ or $6-{ }^{3} \mathrm{H}$ glycosamine [5]. Purified heparins and other GAG molecules can be iodinated to quantify GAG-binding surface molecules of intact microbes in an analogous manner to that used for determining Fn-binding surface proteins (FnBPs) and other ECM-binding proteins [3]. This method is also applicable to the discrimination of specific from non-specific binding in competition experiments that pre-incubate virus, bacterial, or parasite suspensions with non-radiolabelled heparan sulphate, Fn and other ECM-associated molecules and cell-surface glycoconjugates. Cell-surface extracts of micro-organisms binding ${ }^{125}$ I-labelled GAG molecules or solubilised virus proteins can be used in similar inhibition assays. The use of glycosidases, as described above, is helpful. Such experiments should also be performed with purified GAG-binding proteins to discriminate binding to specific proteins from binding to other surface molecules that can bind sulphated and non-sulphated charged molecules such as RNA and nucleotides to 'histone-like' intracellular proteins and heat-shock or stress proteins (HSP) of the GroEl class (60, 70 and $90 \mathrm{kD}$ ). These include those found in $H$. pylori [34], chlamydiae [35, 36], Candida albicans [37,38] and other microbes that bind heparin, other GAGs, sulphatides and sialylated glycoconjugates. In $H$. pylori, a surface-associated $17-\mathrm{kDa}$ protein has been reported to bind all these charged molecules and sulphated gastric and intestinal mucins (B. Appelmelk, personal communication; T. Wadström, unpublished observation). Moreover, as certain phosphated molecules, e.g., ATP, bind to specific binding domains of protein toxins such as Clostridium difficile type A toxin (S. P. Borriello, unpublished observation), a wide range of phosphated, sulphated and sialylated compounds should be investigated to define specificity in the binding properties of GAGBPs before defining GAG proteoglycan-specific cell and ECM receptors for various microbes [23]. Interestingly, a prion molecule has been reported to bind specifically to sialylated glycopeptides derived from laminin in a similar fashion to that reported for sialic acid-specific haemagglutinins or lectins of $H$. pylori and S-fimbriate E. coli [24]. Studies on heparin binding by the major fimbrial subunit, Fim2, of the respiratory tract pathogen Bordetella pertussis used maltose-binding protein-Fim2 fusion proteins, deletions thereof, and site-directed mutagenesis to show that the basic amino acids lysine and tyrosine were important for binding to sulphated sugars [39].

Biotinylation of heparin and other GAG molecules has been used as a tool in several investigations [9]. Stearns et al. synthesised three heparin moieties and used them as probes to detect heparin-binding proteins (HEBPs) [40]. This may be a valuable alternative method, particularly when the ligand is sparse. Heparin and other GAG molecules are highly negatively charged. Thus, it is important to elucidate whether binding is a result of charge interactions. If binding occurs to sulphate, it is likely that binding will be mediated to several of the sulphated GAGs. Keller has emphasised the importance of defining specificity of heparin or heparan sulphate - protein interactions [41]. Finally, the $\mathrm{pH}$ optimum should be defined, as well as the ionic strength and affinity constant $(\mathrm{Kd})$ by Scatchard plot analysis.

Analysis, with calculation of the number of GAGbinding molecules, can be carried out if the molecular mass of these molecules has been defined by purification, e.g., by affinity chromatography or by identifying GAG-binding molecules in SDS-PAGEnitrocellulose membrane blotting. Table 3 [42] shows the results from ${ }^{125}$ I-heparin binding to specific surface molecules of $S$. aureus, Str. pyogenes and $H$. pylori. It should be noted that the $S$. aureus and $S t r$. pyogenes molecules bind with low affinity and low specificity because various charged molecules partially inhibit ${ }^{125} \mathrm{I}$-heparan sulphate binding; this is in contrast to results with $H$. pylori [42].

\section{Glycosaminoglycan binding in microbial adhesion to mucosal surfaces}

Examination of the binding properties of ${ }^{125} \mathrm{I}$-heparan sulphate with sialoglycoconjugates, and haemagglutina-

Table 3. Characteristics of ${ }^{125} \mathrm{I}$-heparan sulphate-binding by three bacterial species

\begin{tabular}{lccc}
\hline Feature & H. pylori & S. aureus & Str. pyogenes \\
\hline $\begin{array}{l}\text { Optimal ionic strength } \\
(\mathrm{M} \mathrm{NaCl})\end{array}$ & $9 \times 10^{-9} \mathrm{M}$ & $3 \times 10^{-5} \mathrm{M}$ & $9.8 \times 10^{-6} \mathrm{M}$ \\
Optimal pH & 4 & & \\
Kd & 0.5 & 0.15 & 0.5 \\
Mol. wt of heparan & $120,72,35$ & 66,60 & 63,58 \\
$\quad$ sulphate-binding & & & \\
$\quad$ proteins (kDa) & & & \\
\hline
\end{tabular}

Data updated from [42]. 
tion assays with fetuin, glycophorins and hyaluronic acid in combination with a great number of 'heparinoids' as potential HA inhibitors, showed that heparininhibitable ${ }^{125}$ I-heparan sulphate binding occurs with all strains of $H$. pylori tested, including so-called class I and II strains as based on the $\operatorname{cag} A$ pathogenicity 'island' [43]. Likewise, expression of sialic acid haemagglutinin and other sialic acid-binding surface lectins (SALs; present in c. $50 \%$ of strains of both class I and II; T. Wadström et al., unpublished results) did not influence binding of heparin. Interestingly, Bord. pertussis expresses a filamentous haemagglutinin (FHA) that binds heparin and other GAG molecules by its C-terminal [44], whereas the B subunit of pertussis toxin binds specific sialoglycoconjugates [45]. However, there are studies suggesting that other surface proteins of the Bord. pertussis FHA recognise both sialo- and sulphated cell glycoconjugates, as such compounds inhibit haemagglutination, unlike $H$. pylori as discussed above [46]. Interestingly, other Helicobacter spp. isolated from animals, such as $H$. felis and H. mustelae, commonly express GAG-binding surface molecules, but not SALs ( $\mathrm{T}$. Wadström et al., unpublished results). Several high mol. wt proteins of Haemophilus influenzae show significant homology to Bord. pertussis FHA and bind heparan sulphate-like molecules in the respiratory epithelium [47]. A common motif involved in this binding includes a peptide sequence rich in basic amino acids flanked by hydrophobic residues (Table 4) [19] and two distant regions of a primary sequence. These may be brought together by a secondary structure to form a binding site. Genomic studies comparing the $H$. pylori genome [48] and Hae. influenzae have not so far revealed FHAlike proteins involved in heparin binding $(\mathrm{M}$. Utt, unpublished observation). Further analysis of the molecular properties of the first $H$. pylori HEBP $(57 \mathrm{kDa})$ will reveal if this protein belongs to a new class of microbial GAGBPs, despite the fact that $H$. pylori and Hae. influenzae are rather closely related organisms according to genomic analysis [48]. Interestingly, HEBP of $M$. tuberculosis and $M$. bovis is also a haemagglutinin that agglutinates rabbit erythrocytes [18].
With Mycoplasma pneumoniae, dextran sulphate has been shown to inhibit adhesion to pulmonary epithelium [49], suggesting that binding of dextran sulphate would mediate adhesion. This has not been followed up. Klotz and Smith [37] were the first to describe the influence of various GAG molecules on the binding of C. albicans to different ECM proteins. In a series of experiments it was shown that GAG molecules and dextran sulphate bind primarily to heparin-binding ECM molecules such as Fn and, in so doing, cover or mask potential binding ligands in ECM for $C$. albicans. Dextran sulphate, which is more highly charged than heparin, did not show any effect, indicating that specific interactions occur between heparin or heparan sulphate and subendothelial ECM [37]. However, a GAG-binding protein has not yet been identified in $C$. albicans.

Bergey and Stinson [11] described heparin-inhibitable binding to ECM basal membranes of Str. pyogenes and Str. mutans, and proposed that these binding properties were possible virulence traits in specific infections caused by these pathogens. Heart tissue GAG binding could target the attachment of microbes to heart valves in subacute endocarditis, and binding to the basement membrane in kidneys could be involved in glomerulonephritis following Str. pyogenes infections. These early observations, as well as the observation that GAG-like molecules and, possibly sulphated glycolipids bind to organisms grown in brain heart infusion broth encouraged a comparison of the influence of various media and culture conditions on expression of GAG binding. GAG-binding proteins of $H$. pylori were expressed optimally in GabCamp broth, unlike production of sialic acid-specific and other $H$. pylori HAs and Lewis-binding proteins which were expressed optimally on solid media such as GabCamp agar $[50,51]$. The opacity factor or Opa adhesin of $N$. gonorrhoeae was expressed when the bacteria were grown in polysaccharide-free medium [52]. Growth in serum or on agar resulted in coverage of the bacterial cells with polysaccharides binding to the Opa adhesin. For the recently described GAGBPs of M. tuberculosis [18] and L. monocytogenes [19],

Table 4. Heparin-binding sequences

\begin{tabular}{lll}
\hline Organism or molecule & Protein & Amino-acid sequence \\
\hline Plasmodium spp. & CS protein & QCNVTCGSIRVRKR \\
& (pepPfl) & \\
Listeria monocytogenes & ActA & Undefined* \\
Herpes simplex virus & gp C & RXXXRCFRXXXR \\
Herpes simplex virus & gp B & KPKKNKKPKPPKP \\
Human immunodeficiency virus & gp 120 & RKSIRIQRGPGRAEVTIGKIG \\
Chlamydia trachomatis & MOMP & Undefined \\
Helicobacter pylori & GAGBP & Undefined \\
Laminin & $\ldots$ & RIQNLLKITNLRIKFVK \\
Antithrombin III & $\ldots$ & KLNCRLYRKANKSSKLVSANR \\
Endothelial cell growth factor & $\ldots$ & KKHEAKNWFVGLKKNGSCKR \\
Apolipoprotein E & $\ldots$ & RKLRKRLLRDAEDLQKRLAV \\
\hline
\end{tabular}

* The sequence in L. monocytogenes is probably very similar to that of Plasmodium spp., as a synthetic peptide of the heparan sulphate-binding ligand, pepPfl, inhibited attachment of Listeria to epithelial cells, and a similar motif was found in the N-terminal of ActA [19]. 
similar studies on expression of these proteins in vitro are lacking. Studies on expression in vivo are also needed. Whereas heparan sulphate and other GAG molecules have been shown to block chlamydia infection in vitro, chlamydia infection was not blocked in a mouse vaginal model of infection [53].

Blecker et al. had already shown in 1969 that heparin inhibits binding of Chlamydia psittaci to tissue culture cells in monolayers, and that dextran sulphate also inhibited binding [35]. More recently, components of the outer-membrane cell envelope of chlamydiae have been shown to bind heparan sulphate and other GAG molecules [54,55], but specific biovariants of the trachoma-Lymphogranuloma venereum (LGV) group also express neuraminidase-sensitive eukaryotic cell receptors [56]. However, as heparin inhibits cell binding of all chlamydiae, the basic mechanism of cell attachment is likely to be common in the genus, thus including 'new' pathogens such as Ch. pneumoniae or TWAR [56]. In brief, cell attachment and infectivity is trypsin-sensitive and is reduced following mild heat treatment of elementary bodies, but cell invasion by these organisms probably also involves other glycoconjugate receptors [57]. Moreover, chlamydiae seem to synthesise heparan sulphate molecules, suggesting a complex interplay of GAG-binding proteins or receptors and GAG molecules in early cell recognition events with this pathogenic prokaryotic intracellular organism [35]. It is likely that this is followed by interaction with other eukaryotic cell receptors, as proposed for heparan sulphate-binding viruses like herpes simplex, which may involve secondary binding to fibroblast growth factor receptors to trigger cell uptake and intracellular multiplication $[2,58]$.

Apart from mediating epithelial adhesion, the $28-\mathrm{kDa}$ HEBP of $M$. tuberculosis and $M$. bovis mediates mycobacterial aggregation which, per se, may promote virulence by formation of microcolonies in vivo at the site of adhesion [18].

\section{Possible role of glycosaminoglycan binding in intracellular survival}

Survival and multiplication of intracellular microorganisms in macrophages and other eukaryotic cells is vital in the pathogenesis of infections caused by such microbes. It has been suggested that GAG-binding surface molecules confer the resistance to phagocytosis seen with L. monocytogenes, $H$. pylori and $N$. gonorrhoeae $[19,20,59]$. It is tempting to speculate that GAG binding may play an important role in intracellular survival in specific cells, such as macrophages, known to express mannose-sialoglycoconjugates and heparan sulphate [60]. Intracellular pathogens known to use heparan sulphate-like molecules in lectinophagocytosis are listed in Table $5[12,18,19$,
Table 5. Intracellular pathogens known to use heparan sulphate-like molecules in lectinophagocytosis

\begin{tabular}{ll}
\hline Organism & Reference \\
\hline Leishmania donovani & {$[61]$} \\
Trypanosoma cruzi & {$[12]$} \\
Plasmodium falciparum & {$[29]$} \\
Helicobacter pylori* & {$[59]$} \\
Listeria monocytogenes & {$[19]$} \\
Mycobacterium tuberculosis & {$[18]$} \\
Yersinia enterocolitica & {$[62]$} \\
\hline
\end{tabular}

*Possibly not an intracellular organism.

$29,59,61,62]$. Specific binding to macrophages has been observed in $H$. pylori, but the heparin-binding haemagglutinin of $M$. tuberculosis does not mediate binding to macrophages $[18,59]$. Further studies on the possible role of GAG binding in intracellular multiplication of chlamydiae seem to be important to understand chronic intracellular survival of these pathogens, including $C h$. pneumoniae, isolated from vascular endothelium of patients with atherosclerosis [63].

However, more in-vitro studies in serum-containing and serum-free systems with macrophages are necessary to define a possible interplay of GAG molecules with individual pathogens. Such studies will form a basis for deciding if GAG molecules such as heparin and various 'heparinoids' can be used in combination with other glycoconjugates to block uptake into macrophages, other professional phagocytes and other target cells in pathogenesis. Such cells include the human gastric epithelium for $H$. pylori, and the urogenital and respiratory tract epithelium for chlamydiae, Bord. pertussis and Hae. influenzae. Another genital tract pathogen, $N$. gonorrhoeae, has been found to interact with various cell types in heparin inhibition experiments [52]. N. gonorrhoeae expressing Opa A, C, F, G and $\mathrm{H}$ [20] absorb various exogenous polyanions such as nucleic acids and heparin. As heparin was found to increase the serum resistance of $\mathrm{Opa}^{+}$compared with Opa ${ }^{-}$gonococci, it has been proposed that cellular GAG molecules shed in genital fluid during infection may bind to $\mathrm{Opa}^{+}$ gonococci and protect them from phagocytosis, in the same way that sialylated capsules can protect $E$. coli K1 strains from phagocytosis in neonatal septicaemia and sialylated lipopolysaccharides can protect gonococci from phagocytosis [52].

\section{Other biological effects}

A number of adhesins to epithelial cells have been identified in Yersinia enterocolitica, including YadA, Ail and Inv [64]. The Yop virulon is a plasmid-encoded virulence apparatus which confers on Yersinia the ability to secrete a number of proteins that inhibit host defence mechanisms and enhance intracellular survival [65]. LcrG has been identified as a regulatory 
component of Yop. LcrG has been shown to bind heparin and dextran sulphate, but not other GAG molecules, and this triggers translocation of Yop effectors inside eukaryotic cells [62]. Presumably, Yersinia cells can utilise heparan sulphate exposed on eukaryotic cells for translocation. Moreover, heparin binding may also interfere with complement and vitronectin binding, and modulate microbe-phagocyte interactions as well as binding to other cells, as shown for C. albicans [26], Pneumocystis carinii [66] and coagulase-negative staphylococci [67]. Epithelial cells undergo rapid apoptosis on loss of contact with the underlying matrix. As several ECM proteins have heparin-binding domains, it is possible that expression of heparin binding by microbes may enhance apoptosis by interfering with the matrix-epithelium contact.

Whether GAG binding may promote invasion of eukaryotic cells by microbes has been a matter of controversy. For herpes simplex, gpB binding of heparan sulphate appears to mediate adhesion, as well as virus-cell fusion and syncytium formation [68], and the cell surface protein ActA of L. monocytogenes mediates both adhesion to professional and nonprofessional phagocytes and internalisation by invasion through the basolateral surface of epithelial cells [69]. For other microbes, it may be more appropriate to refer to GAG adhesion as an initial, sometimes irreversible, adhesion leading to tight adherence, internalisation and inflammatory responses which may be mediated by activation of other receptor molecules [70].

At least three growth factors require heparin for activation. These are acidic fibroblast growth factor (aFGF), basic fibroblast growth factor (bFGF) and platelet-derived growth factor (PDGF). The finding that $S$. aureus and coagulase-negative staphylococci, as well as $H$. pylori, can bind bFGF and PDGF specifically $[71,72]$ may indicate that binding of heparin or growth factors by pathogens can interfere with wound healing in various organs. In addition, it has been suggested that heparan sulphate-growth factor interactions target Pseudomonas aeruginosa exotoxin to susceptible cells [73].

It can be speculated that GAG binding of rather low specificity occurs with surface proteins expressing basic amino acid-rich surface domains, followed by interactions with various acidic molecules in body secretions and serum, and that this may be important in creating 'disguised' organisms. Furthermore, surface domains may express proteins rich in hydrophobic domains ('hydrophobins') of importance for the pathogen to evade a strong immune response [74]. Thus, studies on gonococci, H. pylori and other GAGbinding pathogens seem to be of great importance because GAGBPs, as mucosal epithelium adhesins, are vaccine antigen candidates, a concept that would also target molecules besides various surface lectins and
ECM-binding proteins to create an anti-adhesion approach for prevention and treatment of infections by a 'non-antibiotic' strategy. Preliminary studies involving the use of modified heparin molecules and specific sialoglycoconjugates to block $H$. pylori GAGBPs and SALs in a BALB/c mouse and a primate model have been promising (X. Wang and $\mathrm{T}$. Wadström, unpublished results; D. Zopf, personal communication).

Despite the fact that early studies showed that binding of heparin to the gp120 viral envelope protein of the human immunodeficiency virus inhibited viral entry into cells, syncytium formation, cytopathic effect, reverse transcriptase and binding to specific basic amino acid-rich domains of the Tat protein involved in attachment of the Tat protein to DNA and RNA [75], no systematic approach has been developed to design GAG-like molecules for use as anti-HIV drugs. However, a study by Howell et al. [31] with low mol. wt (LMW) commercial heparin (intended for conventional anticoagulant therapy) showed promising therapeutic results with few side-effects when used for self-administration subcutaneously twice daily in a pilot study. It was suggested that LMW heparin may well show synergy when used with other antiretrovirus therapies.

Standard commercial heparin and LMW heparin (Fragmin) were shown to disrupt rosette formation between $P$. falciparum and both infected and noninfected red blood cells from patients with cerebral malaria [29]. A heparin fraction with low affinity for antithrombin III was equally as effective in disrupting such malaria parasite-induced cell rosettes. These findings suggest that GAG molecules may be true cell receptors on endothelial cells in the brain and on specific cells in other organs such as the liver and placenta. Other investigators have confirmed this proposal and shown that chondroitin-4-suphate is the natural receptor for Plasmodium spp. in the placenta, and is probably involved in transmission of the parasite from the mother to the fetus $[17,76]$.

Altogether, these findings suggest that modified LMW heparin and other GAG molecules, or heparinoids, are indeed candidates for future development of antibacterial, antiviral and antiparasitic drugs. Interestingly, chronic parasitic infections such as leishmaniasis and trypanosomiasisis are caused by parasites that use GAG molecules during early or late stages of infections for cell entry and trans-cell ECM-like interactions. Are there reasons to delay these developments when there is a great need for development of new antimicrobial drugs? It is known that pentasaccharide sequences in heparin and other GAG molecules synthesised by capillary endothelia and other cells in various body tissues show significant heterogeneity, and that this affects binding to a great variety of heparin-binding proteins in serum and other body 
tissues [77]. These heparin-binding proteins can be subdivided into five major groups: i.e., chemokines, cytokines, ECM proteins, heparin-dependent growth factors, growth factor-binding proteins and a number of enzymes such as superoxide dismutase (Table 6). Moreover, GAGs are potent inhibitors of leucocyte rolling in the order heparin-chondroitin-6-sulphate, heparan sulphate and chondroitin-4-sulphate $[32,78]$. It has been shown that this phenomenon is affected by a higher sulphate content in heparin and the position of sulphate groups in GAG molecules. These molecules also interact with $\mathrm{L}$ selectin on leucocytes and bind these cells to the endothelium, while E selectins recognise sialylated tetrasaccharides, such as Lewis $\mathrm{X}$ $[32,78]$. Interestingly, some partly desulphated heparin derivatives have been tested for their effect on leucocyte-cell adhesion, which was shown to differ for 2-O desulphated, 2-O N-desulphated and $\mathrm{N}-$ desulphated heparin, suggesting that overall sulphate content, as well as regional sulphate density or specific sulphate groups, affect binding properties. It seems most likely that studies with such modified heparin molecules will reveal interesting differences in binding to various microbial GAG-binding proteins. Further studies in this area are necessary before candidate drug molecules can be developed as antiviral and antimicrobial drugs. Such studies should involve proteoglycans derived from target organs in specific situations in view of reports that $B$. burgdorferi may use decorin as a specific target molecule in joints in the development of arthritis in Lyme disease [21]. The observation that chondroitin-6-sulphate mediates adhesion of $P$. falciparum-infected erythrocytes to cerebral venular endothelium, but not heparin or heparan sulphate, suggests that a systematic study should involve various developmental stages of parasites other than $P$. falciparum [17]. The same is most likely true for intracellular pathogens such as $M$. tuberculosis and the various pathogenic Chlamydia spp. This is also of great importance in the development of GAG-based therapy to prevent tumour metastasis, where heparin and heparin-degrading enzyme inhibitors may inhibit tumour growth and tumour spread.

Table 6. Examples of heparin-binding proteins

\begin{tabular}{ll}
\hline Type of molecule & Heparin-binding proteins \\
\hline Growth factors & $\begin{array}{c}\text { Fibroblast, epithelial and endothelial } \\
\text { growth factors, platelet-derived growth } \\
\text { factor, TGF } \beta\end{array}$ \\
$\begin{array}{l}\text { Growth factor-binding } \\
\text { proteins }\end{array}$ & $\begin{array}{l}\text { Folliastatin } \\
\text { Cytokines } \\
\text { Chemokines }\end{array}$ \\
& TNF $\alpha$ IL-3, IL-8, IFN- $\chi$, GM-CSF \\
& RANTES, macrophage inflammatory \\
Extracellular matrix & protein 1 monocyte chemoattractant \\
proteins & $\begin{array}{c}\text { Fibronectin, laminin, thrombospondin, } \\
\text { collagens, vitronectin }\end{array}$ \\
Enzymes & Cathepsin G, elastase, superoxide \\
& dismutase
\end{tabular}

The finding that a number of GAG- and ECM-binding micro-organisms, such as group A streptococci, $S$, aureus, E. coli, B. burgdorferi and $H$. pylori, bind and activate tissue and ECM-associated plasminogen to proteolytically active plasmin [79-83] suggests that several analogies may exist between (i) tumour growth and spread, and (ii) interplay between GAG binding and GAG and ECM degradation by specific enzymes involved in normal tissue regeneration and repair. A correlation between basement membrane heparan sulphate and normal epidermal proliferation in wounds has been suggested [84]. GAG-binding microbes can down-regulate tissue repair efficiently by destabilising heparin-dependent growth factors, as proposed for chronic herpes simplex mucosal infections and in $H$. pylori chronic type $\mathrm{B}$ gastritis and peptic ulcer disease [72]. Finally, GAG molecules are associated with cell release and ECM association of various chemokines and cytokines such as interleukin-8 (IL-8) and RANTES (Table 6), suggesting a role for GAG-like molecules in allergy and chronic mucosal surface inflammation in various organs. This is of relevance for $H$. pylori-induced type $\mathrm{B}$ gastritis, ulcerative colitis and other forms of inflammatory bowel disease. Reports of positive results with local heparin treatment on the healing process in the rectal mucosa of patients with ulcerative colitis suggest that further studies are warranted on the role of tissue GAG molecules in the normal gastrointestinal tract and inflamed mucosa [85]. Similarly, in the oral cavity, microbes involved in chronic periodontal disease, such as Prevotella spp. and Porphyromonas gingivalis, have been shown to bind specific ECM molecules, but have not yet been investigated for GAG-binding properties [86]. Reduced expression of heparan sulphate and syndecan-1 has been observed in inflamed human periodontium [87], which may suggest degradation by adhering microorganisms. If so, this may be an important area for future prophylaxis. It is known that specific binding sequences of microbial lectins and, probably, GAGbinding proteins are usually well-preserved genetically compared with other parts of these ligands. It is probable that genetic characterisation of GAGBPs will define GAG-binding peptides which can also be used as tests for anti-adhesion and anti-infectious effects, analogous to those seen with a $\mathrm{Fn} 45-\mathrm{kDa}$ fragment (Telios, San Diego, CA, USA) and specific binding domain sequences of staphylococcal FNBPs, used to block $C$. albicans and $S$. aureus infections, respectively.

\section{Conclusions}

The data showing that a number of microbes may use GAG-binding proteins as adhesins, and the further involvement of GAG molecules during subsequent stages of the infectious process, make GAG molecules promising therapeutic agents. Studies with a Bord. pertussis vaccine based on the fimbrial haemagglutinin 
(FHA) $[88,89]$ allow the proposal that GAG-binding proteins are suitable candidates to be incorporated in future vaccines against a number of microbial pathogens, such as chlamydiae, $H$. pylori, $M$. tuberculosis, malaria and Leishmania parasites, as well as viruses such as herpes simplex, CMV and HIV. The use of heparin or other GAG molecules to block adhesion is also attractive, as these substances are produced naturally by the human body. Therefore, allergic reactions and induction of antibodies are rare, although the latter has been reported in patients with renal failure [90].

The cited studies by the authors were supported by the Swedish MRC (grants $16 x-4723$ and $6 x-11229$.)

\section{References}

1. Rostand KS, Esko JD. Microbial adherence to and invasion through proteoglycans. Infect Immun 1997; 65: 1-8.

2. Norkin LC. Virus receptors: implications for pathogenesis and the design of antiviral agents. Clin Microbiol Rev 1995; 8: 293-315.

3. Ljungh $\AA$, Wadstöm T. Binding of extracellular matrix proteins by microbes. In: Doyle RJ, Ofek (eds) Adhesion of microbial pathogens. Methods in enzymology, vol 253. New York, Academic Press. 1995: 501-514.

4. Ljungh $\AA$, Moran AP, Wadström $\mathrm{T}$. Interactions of bacterial adhesins with extracellular matrix and plasma proteins: pathogenic implications and therapeutic possibilities. FEMS Immunol Med Microbiol 1996; 16: 117-126.

5. Conrad HE. Heparin-binding proteins. San Diego, Academic Press. 1998.

6. Vlodavsky I, Bar-Shavit R, Korner G, Fuks Z. Extracellular matrix-bound growth factors, enzymes and plasma proteins. In: Rohrbach DH, Timpl R (eds) Basement membranes: cellular and molecular aspects. Orlando, Academic Press. 1993: $327-342$.

7. Wadström T, Trust TJ. Bacterial lectins. In: Easmon CSF, Jeljaszewicz J (eds) Medical microbiology IV. London, Academic Press. 1984: 287-334.

8. WuDunn D, Spear PG. Initial interaction of Herpes simplex virus with cells is binding to heparan sulfate. $J$ Virol 1989; 63: $52-58$.

9. Utt M, Wadström T. Identification of heparan sulphate binding surface proteins of Helicobacter pylori: inhibition of heparan sulphate binding with sulphated carbohydrate polymers. $J$ Med Microbiol 1997; 46: 541-546.

10. Liang OD, Ascencio F, Fransson L- $\AA$, Wadström T. Binding of heparan sulfate to Staphylococcus aureus. Infect Immun 1992; 60: $899-906$.

11. Bergey EJ, Stinson MW. Heparin-inhibitable basement membrane-binding protein of Streptococcus pyogenes. Infect Immun 1988; 56: 1715-1721.

12. Ortega-Barria E, Pereira MEA. A novel T. cruzi heparinbinding protein promotes fibroblast adhesion and penetration of engineered bacteria and trypanosomes into mammalian cells. Cell 1991; 67: 411-421.

13. Ouaissi MA, Dutoit E, Vernes A, Guerret-Stocker S, Capron A. In vitro inhibition of Plasmodium falciparum merozoite invasion by human plasma fibronectin. Parasitology 1985; 90: $227-236$

14. Lahav J. The functions of thrombospondin and its involvement in physiology and pathophysiology. Biochim Biophys Acta 1993; 1182: 1-14.

15. Pancake SJ, Holt GD, Mellouk S, Hoffman SL. Malaria sporozoites and circumsporozoite proteins bind specifically to sulfated glycoconjugates. J Cell Biol 1992; 117: 1351-1357.

16. Kulane A, Ekre H-P, Perlmann P, Rombo L, Wahlgren M, Wahlin B. Effect of different fractions of heparin on Plasmodium falciparum merozoite invasion of red blood cells in vitro. Am J Trop Med Hyg 1992; 46: 589-594.

17. Rogerson SJ, Chaiyaroj SC, Ng K, Reeder JC, Brown GV.
Chondroitin sulfate A is a cell surface receptor for Plasmodium falciparum-infected erythrocytes. $J$ Exp Med 1995; 182: 15-20.

18. Menozzi FD, Rouse JH, Alavi M. et al. Identification of a heparin-binding hemagglutinin present in mycobacteria. $J$ Exp Med 1996; 184: 993-1001.

19. Alvarez-Domínguez C, Vázquez-Boland J-A, Carrasco-Marín E, López-Mato P, Leyva-Cobián F. Host cell heparan sulfate proteoglycans mediate attachment and entry of Listeria monocytogenes, and the listerial surface protein ActA is involved in heparan sulfate receptor recognition. Infect Immun 1997; 65: 78-88.

20. Chen T, Swanson J, Wilson J, Belland RJ. Heparin protects $\mathrm{Opa}^{+}$Neisseria gonorrhoeae from the bactericidal action of normal human serum. Infect Immun 1995; 63: 1790-1795.

21. Guo BP, Norris SJ, Rosenberg LC, Höök M. Adherence of Borrelia burgdorferi to the proteoglycan decorin. Infect Immun 1995; 63: 3467-3472.

22. Alderete JF, Baseman JB. Serum lipoprotein binding by Treponema pallidum: possible role for proteoglycans. Genitourin Med 1989; 65: 177-182.

23. Chen Y, Maguire T, Hileman RE et al. Dengue virus infectivity depends on envelope protein binding to target cell heparan sulfate. Nat Med 1997; 3: 866-871.

24. Hart CA. Prion disease. Br J Hosp Med 1996; 56: 64-65.

25. Lane DA, Lindahl U. Heparin. London, Edward-Arnold, 1989.

26. Limper AH, Standing JE. Vitronectin interacts with Candida albicans and augments organism attachment to the NR8383 macrophage cell line. Immunol Lett 1995; 42 139-144.

27. Avila JL, Rojas M, Velazquez-Avila G, von der Mark H, Timpl $\mathrm{R}$. Antibodies to basement protein nidogen in Chagas' disease and American cutaneous leishmaniasis. J Clin Microbiol 1986; 24: $775-778$.

28. Frevert, U, Sinnis P, Cerami C, Shreffler W, Takacs B, Nussenzweig V. Malaria circumsporozoite protein binds to heparan sulfate proteoglycans associated with the surface membrane of hepatocytes. J Exp Med 1993; 177: 1287-1298.

29. Carlson J, Ekre H-P, Helmby H, Gysin J, Greenwood BM, Wahlgren M. Disruption of Plasmodium falciparum erythrocyte rosettes by standard heparin and heparin devoid of anticoagulant activity. Am J Trop Med Hyg 1992; 46: 595-602.

30. Vaheri A. Heparin and related polyionic substances as virus inhibitors. Acta Pathol Microbiol Scand 1964; Suppl 171: $1-98$.

31. Howell AL, Taylor TH, Miller JD, Groveman DS, Eccles EH, Zacharski LR. Inhibition of HIV-1 infectivity by low molecular weight heparin. Results of in vitro studies and a pilot clinical trial in patients with advanced AIDS. Int J Clin Lab Res 1996; 26: $124-131$.

32. Tyrrell DJ, Kilfeather S, Page CP. Therapeutic uses of heparin beyond its traditional role as an anticoagulant. Trends Polysacch Sci 1996; 16: 198-204.

33. Prioli RP, Roenberg I, Pereira MEA. Specific inhibition of Trypanosoma cruzi neuraminidase by the human plasma glycoprotein 'cruzin'. Proc Natl Acad Sci USA 1987; 84: 3097-3101.

34. Yamaguchi $\mathrm{H}$, Osaki $\mathrm{T}$, Kurihara $\mathrm{N}$ et al. Heat-shock protein 60 homologue of Helicobacter pylori is associated with adhesion of $H$. pylori to human gastric epithelial cells. $J$ Med Microbiol 1997; 46: 825-831.

35. Stephens RS. Molecular mimicry and Chlamydia-host cell interactions. In: Mårdh PA, La Placa $M$, Ward M (eds) Proceedings of the European Society for Chlamydia research. Uppsala, Uppsala University Centre for STD Research. 1992: 5-9.

36. Yi Y, Yang X, Brunham RC. Autoimmunity to heat shock protein 60 and antigen-specific production of interleukin-10. Infect Immun 1997; 65: 1669-1674.

37. Klotz SA, Smith RL. Glycosaminoglycans inhibit Candida albicans adherence to extracellular matrix proteins. FEMS Microbiol Lett 1992; 99: 205-208.

38. Swoboda RK, Bertram G, Budge S, Gooday GW, Gow NAR, Brown AJP. Structure and regulation of the HSP90 gene from the pathogenic fungus Candida albicans. Infect Immun 1995; 63: $4506-4514$.

39. Geuijen CAW, Willems RJL, Hoogerhout P, Puijk WC, Meloen $\mathrm{RH}$, Mooi FR. Identification and characterization of heparin binding regions of the Fim2 subunit of Bordetella pertussis. Infect Immun 1998; 66: 2256-2263. 
40. Stearns NA, Prigent-Richard S, Letourneur D, Castellot JJ. Synthesis and characterization of highly sensitive heparin probes for detection of heparin-binding proteins. Anal Biochem 1997; 247: 348-356.

41. Keller JM. Specificity in heparin/heparan sulphate-protein interactions. Glycobiology 1994; 4: 1-2.

42. Ascencio F, Liang OD, Schmidt KH, Fransson L-Å, Wadström $\mathrm{T}$. Comparative studies on heparin- and heparan sulfate-binding bacterial lectins. In: van Driessche $\mathrm{E}$, Franz $\mathrm{H}$, Beeckmans $\mathrm{S}$ Pfüller U, Kallikorm A, Bög-Hansen TC (eds) Lectins. Hellerup, Textop. 1993: 235-242.

43. Covacci A, Rappuoli R. Helicobacter pylori: molecular evaluation of a bacterial quasi-species. Curr Opin Microbiol 1998; 1: 96-102.

44. Hannah JH, Menozzi FD, Renauld G, Locht C, Brennan MJ Sulfated glycoconjugate receptors for the Bordetella pertussis adhesin filamentous hemagglutinin (FHA) and mapping of the heparin-binding domain of FHA. Infect Immun 1994; 62: 5010-5019.

45. van't Wout J, Burnette WN, Mar VL, Rozdzinski E, Wright SD, Tuomanen EI. Role of carbohydrate recognition domains of pertussis toxin in adherence of Bordetella pertussis to human macrophages. Infect Immun 1992; 60: 3303-3308.

46. Sandros J, Tuomanen E. Attachment factors of Bordetella pertussis: mimicry of eukaryotic cell recognition molecules. Trends Microbiol 1993; 1: 192-195.

47. Noel GJ, Love DC, Mosser DM. High-molecular-weight proteins of nontypeable Haemophilus influenzae mediate bacterial adhesion to cellular proteoglycans. Infect Immun 1994; 62: 4028-4033.

48. Tomb J-F, White O, Kerlavage AR et al. The complete genome sequence of the gastric pathogen Helicobacter pylori. Nature 1997; 388: $539-547$.

49. Krivan HC, Olson LD, Barile MF, Ginsburg V, Roberts DD Adhesion of Mycoplasma pneumoniae to sulfated glycolipids and inhibition by dextran sulfate. $J$ Biol Chem 1989; 264: 9283-9288.

50. Guruge JL, Falk PG, Lorenz RG et al. Epithelial attachment alters the outcome of Helicobacter pylori infection. Proc Natl Acad Sci USA 1998; 95: 3925-3930.

51. Ilver D, Arnqvist A, Ögren J et al. Helicobacter pylori adhesin binding fucosylated histo-blood group antigens revealed by retagging. Science 1998; 279: 373-377.

52. van Putten JPM, Hayes SF, Duensing TD. Natural proteoglycan receptor analogs determine the dynamics of Opa adhesinmediated gonococcal infection of Chang epithelial cells. Infect Immun 1997; 65: 5028-5034.

53. Burillo CA, Fontenot JD, Phillips DM. Sulfated polysaccharides block chlamydia infection in vitro, but do not protect mice from vaginal inoculation. Microb Pathog 1998; 24: 253-256.

54. Chen JC-R, Zhang JP, Stephens RS. Structural requirements of heparin binding to Chlamydia trachomatis. J Biol Chem 1996; 271: $11134-11140$

55. Chen JC-R, Stephens RS. Chlamydia trachomatis glycosaminoglycan-dependent and independent attachment to eukaryotic cells. Microb Pathog 1997; 22: 23-30.

56. Kuo C-C, Jackson LA, Campbell LA, Grayston JT. Chlamydia pneumoniae (TWAR). Clin Microbiol Rev 1995; 8: 451-461.

57. Stephens RS. Molecular mimicry and Chlamydia trachomatis infection of eukaryotic cells. Trends Microbiol 1994; 2: 99-101.

58. Baird A, Klagsbrun M. The fibroblast growth factor family. Ann NY Acad Sci 1991; 638.

59. Chmiela M, Czkwianianc E, Wadström T, Rudnicka W. Role of Helicobacter pylori surface structures in bacterial interaction with macrophages. Gut 1997; 40: 20-24.

60. Ernst JD. Macrophage receptors for Mycobacterium tuberculosis. Infect Immun 1998; 66: 1277-1281.

61. Love DC, Esko JD, Moser DM. A heparin-binding activity on leishmania amastigotes which mediates adhesion to cellular proteoglycans. J Cell Biol 1993; 123: 759-766.

62. Boyd AP, Sory M-P, Iriarte M, Cornelis GR. Heparin interferes with translocation of Yop proteins into HeLa cells and binds to LcrG, a regulatory component of the Yersinia Yop apparatus. Mol Microbiol 1998; 27: 425-436.

63. Coles KA, Plant AJ, Riley TV, Smith DW. Cardiovascular disease: an infectious aetiology? Rev Med Microbiol 1998; 9 $17-27$.

64. Yang Y, Isberg RR. Cellular internalization in the absence of invasin expression is promoted by the Yersinia pseudotuberculosis yadA product. Infect Immun 1993; 61: 3907-3913.

65. Cornelis GR, Wolf-Watz H. The Yersinia Yop virulon: a bacterial system for subverting eukaryotic cells. Mol Microbiol 1997; 23: 861-867.

66. Limper AH, Standing JE, Hoffman OA, Castro M, Neese LW. Vitronectin binds to Pneumocystis carinii and mediates organism attachment to cultured lung epithelial cells. Infect Immun 1993; 61: 4302-4309.

67. Lundberg $\mathrm{F}$, Lea $\mathrm{T}$, Ljungh $\AA$. Vitronectin-binding staphylococci enhance surface-associated complement activation. Infect Immun 1997; 65: 897-902.

68. Spear PG, Shieh MT, Herold BC, WuDunn D. Cell surface receptors required for Herpes simplex virus infection include heparan sulfate glucoseaminoglycans. In: Höök M (ed) Molecular mechanisms of microbial adhesion II. New York: Springer Verlag. 1992: 43-58.

69. Temm-Grove $\mathrm{C}$, Jockusch BM, Rohde $M$, Niebuhr $\mathrm{K}$, Chakraborty T, Wehland J. Exploitation of microfilament proteins by Listeria monocytogenes: microvillus-like composition of the comet tails and vectorial spreading in polarized epithelial sheets. $J$ Cell Sci 1994; 107: 2951-2960.

70. Hoepelman AIM, Tuomanen EI. Consequences of microbial attachment: directing host cell functions with adhesins. Infect Immun 1992; 60: 1729-1733.

71. Pascu C, Ljungh $\AA$, Wadström T. Staphlococci bind heparinbinding host growth factors. Curr Microbiol 1996; 32: 201-207

72. Ascencio F, Hansson H-A, Larm O, Wadström T. Helicobacter pylori interacts with heparin and heparin-dependent growth factors. FEMS Immunol Med Microbiol 1995; 12: 272.

73. Mesri EA, Ono M, Kreitman RJ, Klagsbrun M, Pastan I. The heparin-binding domain of heparin-binding EGF-like growth factor can target Pseudomonas exotoxin to kill cells exclusively through heparin sulfate proteoglycans. J Cell Sci 1994; 107: 2599-2608

74. Ofek I, Goldhar J, Keisari Y, Sharon N. Nonopsonic phagocytosis of microorganisms. Annu Rev Microbiol 1995; 49: $239-276$.

75. Bagasra $\mathrm{O}$, Whittle $\mathrm{P}$, Heins $\mathrm{B}$, Pomerantz RJ. Anti-human immunodeficiency virus type 1 activity of sulfated monosaccharides: comparison with sulfated polysaccharides and other polyions. J Infect Dis 1991; 164: 1082-1090.

76. Maubert B, Guilbert LJ, Deloron P. Cytoadherence of Plasmodium falciparum to intercellular adhesion molecule 1 and chondroitin-4-sulfate expressed by the syncytiotrophoblast in the human placenta. Infect Immun 1997; 65: 1251-1257.

77. Zugmaier G, Lippman ME, Wellstein A. Inhibition by pentosan polysulfate (PPS) of heparin-binding growth factors released from tumor cells and blockage by PPS of tumor growth in animals. $J$ Natl Cancer Inst 1992; 84: 1716-1724.

78. Lasky LA. Selectins: interpreters of cell-specific carbohydrate information during inflammation. Science 1992; 258: 964-969.

79. Kuusela P, Ullberg M, Saksela O, Kronvall G. Tissue-type plasminogen activator-mediated activation of plasminogen on the surface of group $\mathrm{A}, \mathrm{C}$, and $\mathrm{G}$ streptococci. Infect Immun 1992; 60: 196-201.

80. Kuusela P, Kaukoranta-Tolvanen S-F, Ullberg M, Kronvall G, Saksela O. Surface associated activation of plasminogen on staphylococci and streptococci, and novel mechanisms for bacteriemia to use the activator system of the host. In: Wadström T, Holder IA, Kronvall G (eds) Molecular pathogenesis of surgical infections. Stuttgart, Gustav Fischer Verlag. 1994: $97-102$

81. Parkkinen J, Korhonen TK. Binding of plasminogen to Escherichia coli adhesion proteins FEBS Lett 1989; 250: 437-440.

82. Hu LT, Pratt SD, Perides G, Katz L, Rogers RA, Klempner MS. Isolation, cloning, and expression of a 70-kilodalton plasminogen binding protein of Borrelia burgdorferi. Infect Immun 1997; 65: 4989-4995.

83. Ringnèr $\mathrm{M}$, Valkonen $\mathrm{KH}$, Wadström $\mathrm{T}$. Binding of vitronectin and plasminogen to Helicobacter pylori. FEMS Microbiol Immunol 1994; 9: 29-34.

84. Andriessen MP, van den Born J, Latijnhouwers MA, Bergers $M$, van de Kerkhof PC, Schalkwijk J. Basal membrane heparan sulphate proteoglycan expression during wound healing in human skin. $J$ Pathol 1997; 183: 264-271.

85. Gaffney PR, Doyle CT, Gaffney A, Hogan J, Hayes DP, Annis P. 
Paradoxical response to heparin in 10 patients with ulcerative colitis. Am J Gastroenterol 1995; 90: 220-223.

86. Kontani M, Kimura S, Nakagawa I, Hamada S. Adherence of Porphyromonas gingivalis to matrix proteins via a fimbrial cryptic receptor exposed by its own arginine-specific protease. Mol Microbiol 1997; 24: 1179-1187.

87. Oksala O, Haapasalmi K, Hakkinen L, Uitto VJ, Larjava H. Expression of heparan sulphate and small dermatan/chondroitin sulphate proteoglycans in chronically inflamed human periodontium. J Dent Res 1997; 76: 1250-1259.
88. Moxon ER. Applications of molecular microbiology to vaccinology. Lancet 1997; 350: 1240-1244.

89. Leininger E, Bowen S, Renauld-Mongénie G et al. Immunodominant domains present on the Bordetella pertussis vaccine component filamentous hemagglutinin. J Infect Dis 1997; 175: 1423-1431.

90. Greinacher A, Zinn S, Wizemann, Birk UW. Heparin-induced antibodies as a risk factor for thromboembolism and haemorrhage in patients undergoing chronic haemodialysis. Lancet 1996; 348: 764 . 